\title{
Endothelin-1 contributes to the development of virus-induced demyelinating disease
}

\author{
Young-Hee Jin ${ }^{1,2,3^{*}}$ D, Bongsu Kang ${ }^{1}$, Hyun S. Kang ${ }^{1}$, Chang-Sung Koh ${ }^{4}$ and Byung S. Kim ${ }^{1 *}$
}

\begin{abstract}
Background: Experimental autoimmune encephalitis (EAE) and virally induced demyelinating disease are two major experimental model systems used to study human multiple sclerosis. Although endothelin-1 level elevation was previously observed in the CNS of mice with EAE and viral demyelinating disease, the potential role of endothelin-1 in the development of these demyelinating diseases is unknown.

Methods and results: In this study, the involvement of endothelin-1 in the development and progression of demyelinating diseases was investigated using these two experimental models. Administration of endothelin-1 significantly promoted the progression of both experimental diseases accompanied with elevated inflammatory $T$ cell responses. In contrast, administration of specific endothelin-1 inhibitors (BQ610 and BQ788) significantly inhibited progression of these diseases accompanied with reduced $T$ cell responses to the respective antigens.

Conclusions: These results strongly suggest that the level of endothelin-1 plays an important role in the pathogenesis of immune-mediated CNS demyelinating diseases by promoting immune responses.
\end{abstract}

Keywords: CNS, EAE, TMEV, Endothelin-1, Demyelination

\section{Introduction}

Theiler's murine encephalomyelitis virus (TMEV) causes a chronic progressive demyelinating disease in susceptible mice $[1,2]$. Development of this virally induced demyelinating disease appears to be immune-mediated and primarily involves $\mathrm{CD} 4^{+} \mathrm{T}$ cells $[3,4]$. Infiltration of proinflammatory $\mathrm{T}$ cells such as Th17 and Tc17 appears to be associated with tissue destruction and demyelination $[5,6]$, similar to multiple sclerosis (MS) [7-9]. In addition, both $\mathrm{T}$ cell and antibody responses to selfantigens are induced in susceptible mice after chronic TMEV infection [10-13]. Therefore, this viral demyelinating disease model in mice has been investigated as a relevant animal model for MS. Infection of cells with

\footnotetext{
* Correspondence: jinohee@kiom.re.kr; bskim@northwestern.edu

${ }^{1}$ Department of Microbiology-Immunology, Northwestern University Feinberg Medical School, 303 East Chicago Avenue, Chicago, IL 60611, USA Full list of author information is available at the end of the article
}

TMEV activates production of various cytokines via TLR- and melanoma differentiation-associated gene 5 (MDA5)-dependent pathways [14-16]. High levels of IL1 or type I IFNs, which are downstream products of TLR or MDA5 activation, play a pathogenic role [17, 18]. Similarly, excessive levels of IL-6 exert a potent pathogenic effect on the development of TMEV-induced demyelinating disease by promoting Th17 responses [5]. Furthermore, TLR-mediated signals induce $\mathrm{PGE}_{2}$ elevation via the NLRP3 pathway to affect the pathogenesis of TMEV-induced demyelinating disease [19].

Moreover, TMEV infection activates production of various chemokines in different glial cell types [20, 21]. These proinflammatory chemokines consequently contribute to cellular infiltration into the CNS and further activation of the infiltrating inflammatory immune cells [22-24], eventually leading to the development and progression of virus-induced demyelinating disease. 
However, very little is known about the role of vascular components such as VEGF in the pathogenesis of TMEV-induced demyelinating disease as VEGF also appears to be associated with pathological changes in MS and its animal models [25-27]. Similarly, endothelin-1 (ET-1) levels appear to affect the pathogenesis of both MS and its animal model disease [28-30]. Therefore, it is valuable to investigate whether ET-1 contributes as a common mechanism in the development of TMEVinduced demyelinating disease.

Several reports indicate that TLR2 and TLR4 agonists induce ET-1 production in human DCs [31]. In addition, TLR3 activation also induced ET-1 production [32, 33]. Since TMEV infection is known to activate various cellular proteins via TLR2 and TLR3 [14, 15, 34], we predict that TMEV infection induces ET-1 via TLR signaling, which may affect the development of TMEV-induced demyelinating disease. ET-1 is produced in many different cell types such as endothelial cells, neurons, and macrophages [35]. ET-1 is associated with the activation of transcription factors such as NF- $\mathrm{kB}$ and expression of proinflammatory cytokines including TNF- $\alpha$, IL-1, and IL-6 [36]. In addition, ET-1 enhances VCAM-1 expression on vascular endothelial cells [37]. In addition, ET-1 induces COX-2 expression and PGE2 production [38]. ET-1 is known to function by engaging with its G-protein-coupled receptors, mainly ETA and ETB [39]. Therefore, it is conceivable that ET-1 induced via TLR activation following TMEV infection may also participate in the pathogenesis of demyelinating disease.

To investigate the aforementioned possibility, we examined the potential role of ET-1 in the development of TMEV-induced demyelinating disease. In this study, we established that TMEV-infected susceptible SJL mice displayed an elevated level of ET-1 compared to uninfected mice. In addition, ET-1 administration significantly promoted progression of TMEV-induced demyelinating disease accompanied with increased cellular infiltration of the CNS and elevated inflammatory T cell responses. These results suggest that the ET-1 induced following TMEV infection contributes to development of viral demyelinating disease. To further investigate this possibility, we administered specific inhibitors (BQ610 and BQ788) for endothelin-1 receptors (ETA and ETB, respectively). These ET-1 receptor inhibitors significantly hindered disease progression accompanied with reduced cellular infiltration of the CNS and $\mathrm{T}$ cell responses to the viral antigens. Therefore, the results of this study strongly suggest that endothelin-1 levels significantly contribute to the pathogenesis of immune-mediated CNS demyelinating diseases by promoting inflammatory immune responses following the neurotrophic TMEV infection.

\section{Materials and methods Animals}

Female SJL/J (SJL) mice (4-6 weeks old) were purchased from Charles River Laboratories (Charles River, MA) through the National Cancer Institute (Frederick, MD). All mice were housed at the Center for Comparative Medicine Facility, Northwestern University. All animal studies used protocols approved by the Institutional Animal Care and Use Committee.

\section{Viruses}

BeAn 8386 strain of TMEV was propagated in BHK-21 cells in Dulbecco's modified Eagle's medium supplemented with $7.5 \%$ donor calf serum. For some experiments, the virus was purified by centrifugation on sucrose gradients, as previously described [40].

\section{Chemicals}

The peptide representing the mature form of endothelin-1 was purchased from Sigma-Aldrich (St. Louis, MO). Endothelin-1 inhibitors, namely, BQ610 for endothelin receptor-A (ETA) and BQ788 for endothelin receptor-B (ETB), were also obtained from Sigma-Aldrich.

\section{Synthetic peptides}

All synthetic peptides were purchased from Genmed Synthesis (San Francisco, CA). Stock peptides of the previously defined TMEV-specific $\mathrm{CD}^{+}\left(\mathrm{VP}_{203-220}\right.$ and $\left.\mathrm{VP}_{425-38}\right)$ and $\mathrm{CD}^{+} \mathrm{T}$ cell epitopes (VP2 $121-130$ and $\mathrm{VP} 3_{110-120}$ ) for SIL mice were prepared in a solution of $8 \%$ dimethylsulfoxide (DMSO) in phosphate-buffered saline (PBS).

\section{TMEV infection}

Viral titer was determined through a plaque assay on BHK cells; this was used to determine the multiplicity of infection. For animal studies, $1 \times 10^{6} \mathrm{PFU}$ of TMEV in $30 \mu \mathrm{l}$ DMEM was injected into the right cerebral hemisphere of female SJL/J mice anesthetized with isoflurane. Clinical symptoms of disease were assessed weekly based on the following grading scale [41]: grade 0 , no clinical signs; grade 1, mild waddling gait; grade 2, moderate waddling gait and hind-limb paresis; grade 3, severe hind-limb paralysis; grade 4, severe hind-limb paralysis and loss of righting reflex; and grade 5 , death.

\section{EAE induction}

SJL/J female mice were subcutaneously immunized twice (days 0 and 7) with PLP $_{139-151}$ (40 $\mu \mathrm{g} /$ mouse) in incomplete adjuvant containing H37RA (100 $\mu \mathrm{g} /$ mouse) according to the injection schedule previously reported [42].

\section{ET-1 and ET receptor antagonist treatment}

One hundred picomoles of $30 \mu \mathrm{l} \mathrm{ET-1}$ containing $1 \times$ $10^{6}$ PFU TMEV was initially injected intracerebrally. 
Thirty days after the first injection, $100 \mathrm{pmol}$ of $30 \mu \mathrm{l}$ ET-1 without TMEV was injected either i.c. or i.v. For experiments involving ET receptor antagonists, PBS (cont), BQ610, or BQ788 (1 mg/kg) was injected i.v. into the SJL mice multiple times at days $0,5,10,15,20,30$, and 46 post-viral infection.

\section{CNS mononuclear cell preparation}

The brains and spinal cords were removed from the mice after perfusion with Hank's balanced salt solution through the left ventricle. Tissues were forced through a steel mesh to prepare single-cell suspensions and were incubated at $37{ }^{\circ} \mathrm{C}$ for $45 \mathrm{~min}$ in $250 \mu \mathrm{g} / \mathrm{ml}$ collagenase type 4 (Worthington Biochemical Corp., Lakewood, NJ, USA). A continuous 100\% Percoll gradient (Pharmacia, Piscataway, NJ, USA) was created by centrifuging at 27 , $000 \times g$ for $30 \mathrm{~min}$ to enrich CNS-infiltrating mononuclear cells as previously described [43].

\section{T cell proliferation assay}

Spleen cells $\left(1 \times 10^{6}\right.$ cells/well $)$ were stimulated with the indicated stimuli in 96 well flat-bottom microtiter plates in RPMI 1640 containing $0.5 \%$ syngeneic mouse serum and 5 $\times 10^{-5} \mathrm{M}$ 2-mercaptoethanol. After incubation with the antigens for $72 \mathrm{~h}$, cultures were pulsed with $1.0 \mu \mathrm{Ci}$ of $\left[{ }^{3} \mathrm{H}\right]$ $\mathrm{TdR}$ and harvested $18 \mathrm{~h}$ later. Measurements of the $\left[{ }^{3} \mathrm{H}\right]$ $\mathrm{TdR}$ uptake by the cells was performed, and these were expressed as counts per minute $(\Delta \mathrm{cpm})+/-\mathrm{SEM})$ after subtracting the background count with PBS. Triplicate cultures were stimulated with either $\operatorname{PLP}_{139-151}(10 \mu \mathrm{g})$ for EAE mice, UV-inactivated TMEV $(1,3 \mu \mathrm{g})$, or TMEV T cell epitope peptides (at $1,10 \mu \mathrm{M}$ of $\mathrm{VP}_{233-250}, \mathrm{VP} 2_{74-86}$, $\mathrm{VP}_{24-37}$ ) for TMEV-infected mice. As an unrelated peptide control, hen egg lysozyme (HEL $\left.\mathrm{H}_{47-61}\right)$ was used.

\section{Histopathological staining}

At 30 and 60 days post-TMEV infection, mice were perfused with $50 \mathrm{ml}$ of PBS via intracardiac puncture. The brain and spinal cords from ET1-treated or untreated SJL mice were dissected, and these were fixed in $4 \%$ formalin in PBS for 4 days, transferred into 30\% sucrose/PBS solution and incubated for $24 \mathrm{~h}$, and embedded in paraffin. Paraffin-processed brain and spinal cord samples were sectioned with a thickness of $6 \mu \mathrm{m}$, and two sets of adjacent sections from each animal were deparaffinized, rehydrated, and separately evaluated using Luxol fast blue (LFB) staining for axonal demyelination, which were then counterstained with hematoxylin and eosin (H\&E) to detect inflammatory infiltrates and Bielschowsky silver staining for observing axon damage and loss.

\section{RT-PCR and real-time PCR}

Total RNA was extracted from the lysates of the brain/ spinal cord cells using TRIzol (Invitrogen, Carlsbad, CA,
USA) according to the manufacturer's instructions. Firststrand cDNA was synthesized using MMLV reverse transcriptase and oligo $(\mathrm{dT})_{18}$ from 1-4 $\mu \mathrm{g}$ total RNA depending on the frequencies of the transcripts. MJ Research, Inc. (Watertown, MA, USA) thermal cycler was used for PCR. Primers were obtained from Integrated DNA Technologies (Coralville, IA, USA). Sense and antisense primer sequences used are as follows: ET-1 (5'-AGAGTGTGTC TACTTCTGCC-3' and 5'-GCGTTATGTGACCC-ACAA C-3'); CCL2 (5'-AGCAGGTGTCCCAAAGAAGCTGTA$3^{\prime}$ and 5'-AGAAGTGCT-TGAGGTGGTTGTGGA-3'); CXCL10 (5' -AAGTGCTGCCGTCATTTTCT-3' and 5' -GTGGCAATGATCTCAACACG-3'); CXCL1 (5'GCTGGGATTCACCTCAAGAA-3' and 5'-TGGGGACA CCT-TTTAGCATC-3'); IFN- $\gamma \quad$ (5'-ACTGGCAAAA GGATGGTGAC-3' and 5'-TGAGCTCATTGAATGC TTGG-3'); IL-17A (5'-CTCCAGAAGGCCCTCA-GACT AC-3' and 5'-AGC-TTTCCCTCCGCATTGACACAG-3'); IL-10; (5'-GCCAAGCCTTATCGGAAATG-ATCC-3' and 5'-AGACACCTTGGTCTTGGAGCTT-3'); IL-12 (5'CAGAAGCTAACC-ATCTCCTGGTTTG-3' and 5'TCCGGAGTAATTTGGTG CTTCACAC-3'); CD4 (5'TGTGCCGAGCCATCTCTCTTAGG-3' and 5'-GCAC TGAGAGTGTCATGCC-GAAC-3'); CD8 (5'-TCTGTC GTG CCAGTCCTTC-3' and 5'-CCTTCCTGTCTGAC TAGC GG-3'); GAPDH (5'-AACTTTGGC-ATTGTGGA AGG-3' and 5'-ACACATTGGGGGTAGGAACA-3'); and TMEV genome (5'-CCCAGTCCTCAGGAAATGAAGG3 ' and 5'-TCCAAAAGG-AGAGGTGCCATAG-3'). For quantitative analysis of gene expression, real-time PCR was performed using the iCycler SYBR Green I master mix and an iCycler Real-Time PCR System (Bio-Rad, Hercules, CA, USA). GAPDH expression was used for normalization of gene expression levels. The expression level represents the fold-increase compared to the lowest values in the group. Real-time PCR reactions were performed in triplicate.

\section{ELISA assay for detection of IFN- $\gamma$ protein}

ELISA was used to assess cytokine levels produced by splenocytes in response to the PLP and TMEV epitopes. Briefly, splenocytes $\left(2-3 \times 10^{6}\right.$ cells/well $)$ from TMEVinfected SJL/J mice were stimulated with various concentrations of either peptides or UV-TMEV for $72 \mathrm{~h}$. Cell-free supernatants were examined for the presence of IFN- $\gamma$ through cytokine capture ELISA using the OptEIA kit (BD Pharmingen, San Diego, CA).

\section{Statistical analyses}

Significant differences (two-tailed $p$ value) between the experimental groups with various treatments and the control group were analyzed through an unpaired Student's $t$ test (unless otherwise indicated) using the InStat Program (GraphPAD Software, San Diego, CA, USA). 
Multiple group comparisons were done using a one-way analysis of variance with Tukey-Kramer post hoc analysis. Values of $p<0.05$ were considered significant.

\section{Results}

Elevated ET-1 mRNA expression in SJL mice after TMEV infection

TLR activation is associated with ET-1 induction, which has been associated with the pathogenesis of MS and shown to contribute to experimental models for the disease. Therefore, we first tested the possibility that SJL mice infected with TMEV exhibit elevated ET-1 levels in the CNS (Fig. 1a). When the ET-1 mRNA levels in the CNS of SJL mice were compared between uninfected and TMEVinfected mice at 8 days post-infection by real time-PCR, ET-1 mRNA was significantly elevated in TMEV-infected mice compared to uninfected mice. This result is consistent with previous observations that TLR activation following viral infection may elevate ET-1 production [32,33].

\section{Exacerbation of TMEV-IDD in SJL mice following administration of ET-1}

To further investigate the possibility that elevated ET-1 production following viral infection affects the pathogenesis of TMEV-induced demyelinating disease, we administered the ET-1 peptide during the viral infection (Fig. 1b). SJL mice ( $n=10$ /group) were infected with a suboptimal dose $\left(1 \times 10^{5} \mathrm{PFU}\right)$ of TMEV. The experimental group was treated with ET-1 $(20 \mu \mathrm{g} / \mathrm{kg})$ and the control group was treated with PBS at days - 3, 0, 5, 10, 15, 20, and 46 with respect to viral infection. The development of clinical symptoms was significantly accelerated $(p<$ $0.0024)$ in mice treated with ET-1 compared to the control mice. ET-1 treated mice also showed elevated levels of chemokines (CCL2 and CXCL1) affecting cellular infiltration at $8 \mathrm{dpi}$ (Fig. 1c upper panel). However, CXCL10 was not elevated in mice treated with ET-1. In addition, the levels of viral RNA and cytokine messages (IFN- $\gamma$ and IL-17A) were significantly increased (Fig. 1c, lower panel). Therefore, ET-1 elevation may affect the upregulation of select chemokines, cytokines, and viral RNA in conjunction with TMEV infection.

\section{Administration of ET-1 increase the infiltration of various inflammatory cells}

Because ET-1 can promote cellular migration into the CNS during inflammatory response [44], the levels of cell types that infiltrated the CNS after TMEV infection were compared between the groups treated with ET-1 and PBS (Fig. 2). Proportions of DCs $\left(\mathrm{CD} 11 \mathrm{c}^{+}\right)$, NK cells $\left(\mathrm{NK} 1.1^{+}\right)$, macrophages $\left(\mathrm{CD} 45^{+} \mathrm{CD} 11 \mathrm{~b}^{\text {high }}\right)$, and granulocytes $\left(\mathrm{Ly} 6 \mathrm{G} / 6 \mathrm{C}^{+}, \mathrm{Gr}-1^{+}\right)$that infiltrated the CNS at $8 \mathrm{dpi}$ were first compared (Fig. 2a). Interestingly, ET-1 treated mice showed significantly higher proportions $(\sim 2$-fold $)$ and numbers of these cell types in the CNS compared to the control group (Fig. 2b). CD11b ${ }^{+}$cells from ET-1treated mice expressed elevated levels of co-stimulatory (CD40, CD80, and CD86) and MHC molecules (H-2K ${ }^{\mathrm{s}}$ and $\left.I-A^{\mathrm{s}}\right)$, as well as PDL-1, compared with those from untreated control mice (Fig. 2c and Additional file 1: Supplementary Figure 1).

\section{Elevation of Th1 responses to viral antigens in TMEV- infected mice receiving ET-1}

To determine whether Th subtype responses are altered in mice treated with ET-1 compared to those in the control mice, mRNA levels of IFN- $\gamma$ and IL-17A in the CNS of virus-infected mice at $8 \mathrm{dpi}$ were determined using quantitative PCR after in vitro re-stimulation with peptides containing CD4 and CD8 T cell epitopes (Fig. 3a). IFN- $\gamma$ mRNA levels in both $\mathrm{CD}^{+}$and $\mathrm{CD}^{+} \mathrm{T}$ cells were significantly higher in mice treated with ET-1 compared to the control mice. However, IL-17 mRNA levels were higher in $\mathrm{CD}^{+} \mathrm{T}$ cells but were lower in $\mathrm{CD}^{+} \mathrm{T}$ cells in ET-1 treated mice. The proliferation and IFN- $\gamma$ secretion of splenocytes from ET-1-treated mice were significantly higher in response to UV-TMEV compared to those in untreated control mice (Fig. 3b).

\section{Histological examinations of TMEV-infected SJL mice treated with ET-1}

To correlate the development of clinical signs with demyelination, the spinal cords (Fig. 4a) and brains (Fig. 4b) of mice infected with TMEV at $30 \mathrm{dpi}$ were histologically assessed. Representative sections showed that there are more infiltrating lymphocytes/macrophages (indicated by arrowhead) that accumulated in the spinal cord (Fig. $4 \mathrm{Ab}$ ) and cerebellum (Fig. $4 \mathrm{Bf}$ ) of the ET-1treated SJL mice infected with TMEV compared to those (Fig. $4 \mathrm{Aa}$ and $\mathrm{Be}$ ) in the control SJL mice. Infiltration mainly occurred in the white matter of the control SJL mice. However, in ET-1-treated SJL mice, infiltrated lymphocyte/macrophages invaded the gray matter of the spinal cord and cerebellum. Bielschowsky silver staining of the adjacent sections (Fig. $4 \mathrm{Ac}, \mathrm{Ad}, \mathrm{Bg}$, and $\mathrm{Bh}$ ) showed axon damage in the demyelination region in both groups and also in the clustered lymphocyte/macrophages infiltrated area in the ET-1 treated mice brain.

\section{Inhibition of the development of TMEV-induced demyelinating disease after administration of ET-1 receptor inhibitors}

To further verify effects of ET-1 on the development of TMEV-induced demyelinating disease, we examined virus-induced demyelination upon administration of SJL mice with ET-1 receptor inhibitors (BQ610 or BQ788) during viral infection. Administration of either ET-1 receptor inhibitor significantly inhibited development of 

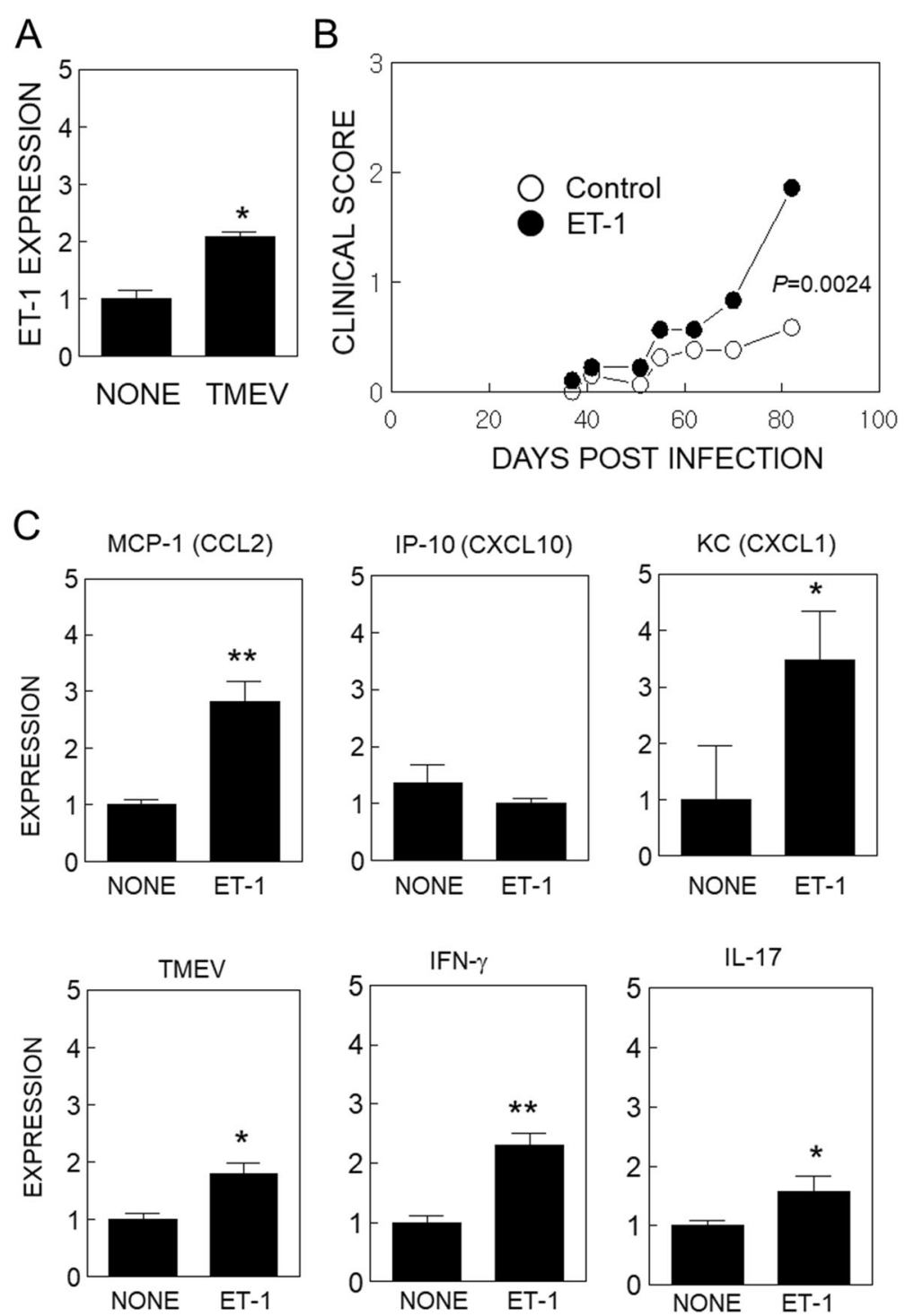

Fig. 1 Effect of endothelin-1 on the development of Theiler's murine encephalomyelitis virus (TMEV)-induced demyelinating disease. a Levels of ET-1 mRNA in the CNS of naïve mice or mice infected with TMEV at 8 dpi. b SJL/J mice ( $n=10 /$ group) were intracerebrally infected with a suboptimal dose $\left(1 \times 10^{5} \mathrm{PFU}\right)$ of TMEV and were treated with either PBS or ET-1 $(20 \mu \mathrm{g} / \mathrm{kg})$ at days $-3,0,5,10,15,20$, and 46 . Disease development was evaluated based on the 5-point scale described in the "Materials and methods" section. The difference between the control and ET-1 groups was significant $(p<0.0024)$ based on the paired two-tailed $t$ test between 37 and 85 dpi. c Relative expression of MCP-1 (CCL2), IP-10 (CXCL-10), KC (CXCL1), TMEV, IFN- $\gamma$, and IL-17A mRNA. Real-time PCR was used to assess expression levels. Data are presented as mean \pm SEM of three independent experiments. ${ }^{*} p<0.05$ and ${ }^{* *} p<0.001$

TMEV-IDD $(p<0.01)$ compared to the control group without any inhibitors (Fig. 5a). The treatment with ETB inhibitor (BQ788) $(p<0.001)$ appears to provide better protection from TMEV-IDD compared to ETA (BQ610) treatment $(p<0.01)$, suggesting that endothelin receptor- $\mathrm{B}$ plays the major role in the pathogenesis of TMEV-IDD. Levels of $\mathrm{T}$ cell proliferative responses and IFN- $\gamma$ production of splenic T cells against UV-TMEV at 27 and $70 \mathrm{dpi}$ were also examined (Fig. 5b). Proliferation responses were significantly lower to UV- inactivated TMEV in mice treated with ET-1 inhibitors. Similarly, IFN- $\gamma$ production of the spleen cells in response to TMEV was lower in these treated mice. In addition, mRNA levels of the TMEV virus, IFN- $\gamma$, IL-10, and IL-12 cytokines, as well as of the CD4 T cell marker, were visibly lower in the CNS of mice treated with ET-1 receptor inhibitors at $27 \mathrm{dpi}$ (Fig. 5c). These results strongly suggest that the administration of ET-1 receptor inhibitors suppresses the development of TMEVinduced demyelinating disease in susceptible SJL mice. 

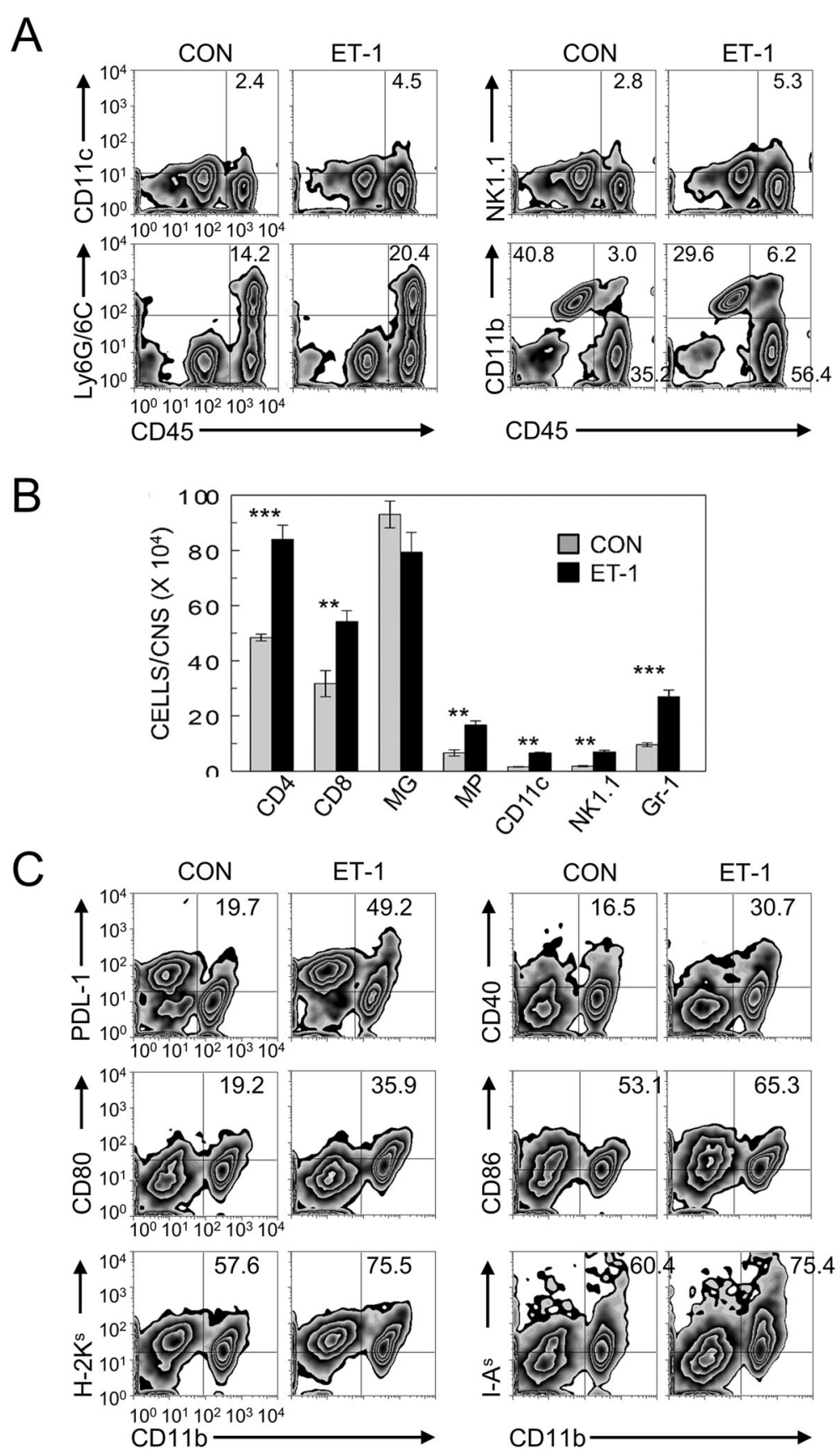

Fig. 2 Effects of endothelin administration on the expression of inhibitory and co-stimulatory molecules on monocytes (CD11 $\left.\mathrm{b}^{+}\right)$in the CNS of infected mice. a Flow cytometric analyses of CNS-infiltrating cells at $8 \mathrm{dpi}$. A representative set of plots is shown. CD11 $\mathrm{c}^{+}$cells between control vs. ET-1 groups of $3-5$ experiments, $2.23 \pm 0.18$ vs. $4.4 \pm 0.11$; NK1. $1^{+}$cells, $2.6 \pm 0.25$ vs. $5.0 \pm 0.37$; Ly6G/6C cells, $13.49 \pm 1.00$ vs. $19.2 \pm 1.69$;

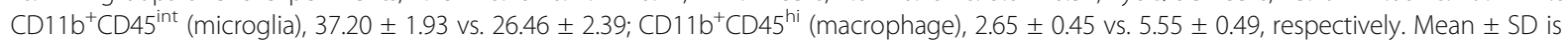
shown for each cell type. $\mathbf{b}$ Cell numbers of the above cell types in the CNS at $8 \mathrm{dpi}$, as determined by flow cytometry, are shown in the histogram. Differences in the cell numbers of the cell types except the microglia are significant. Data are presented as mean \pm SEM of three independent experiments. ${ }^{* *} p<0.001$ and ${ }^{* * *} p<0.0001$. c Expression levels of inhibitory (PDL-1) and co-stimulatory molecules (CD40, CD80, CD86, and MHC) on the CNS CD11 b+ cells in TMEV-infected mice treated with either PBS or ET-1 at $8 \mathrm{dpi}(n=3)$. The number indicated the \% of marker expressed cells of total CD11 $b^{+}$cell. Data are representative of three independent experiments 


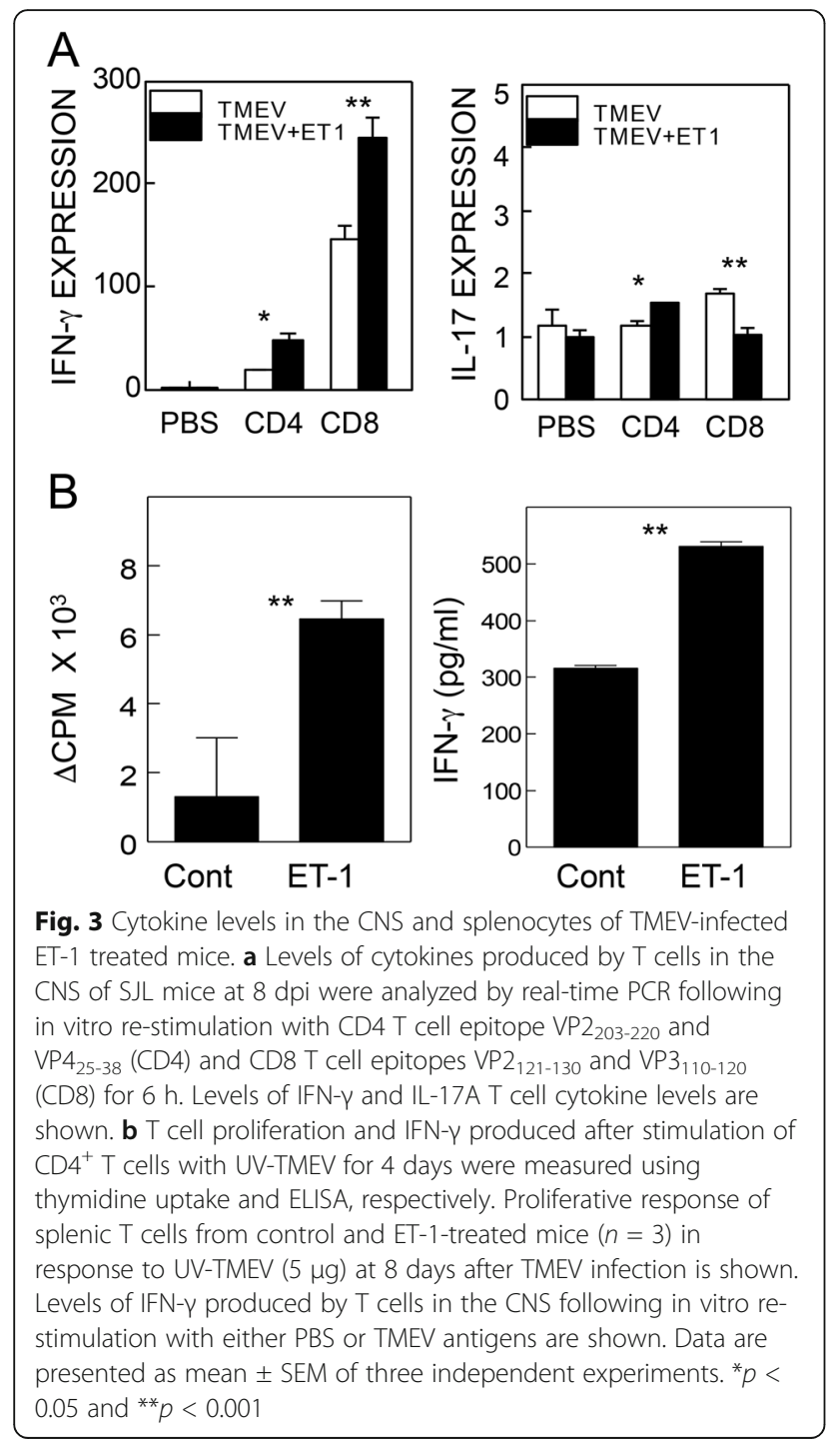

\section{Administration of ET-1 accelerated the development of PLP-induced EAE}

Previously, it was shown that EAE development in transgenic mice overexpressing ET-1 with $\mathrm{MOG}_{35-55}$ is exacerbated [30]. To further compare the effect of ET-1 administration on the development of TMEVIDD with the development of autoimmune-mediated demyelinating disease, SJL/J mice were immunized with the $\mathrm{PLP}_{139-151}$ peptide and were treated with either PBS or ET-1 (Fig. 6). The level of EAE development in SJL mice that received ET-1 was significantly $(p<0.001)$ elevated compared to control mice treated with PBS (Fig. 6a). Levels of CD4, CD8, and inflammatory cytokine (IFN- $\gamma$, IL-10, and IL12) mRNA in the CNS of ET-1 treated mice were also higher compared to the control mice (Fig. 6b). In addition,

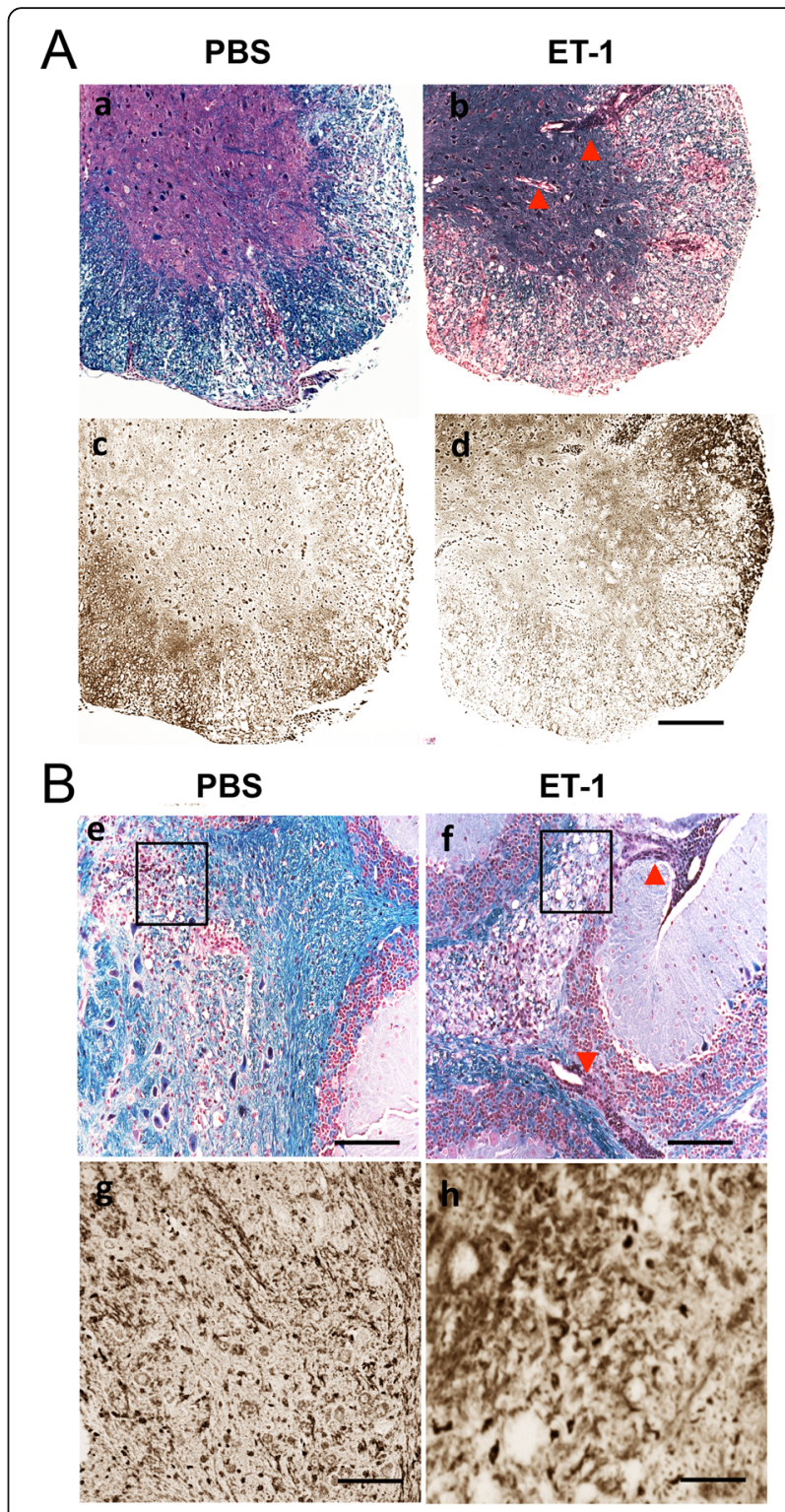

Fig. 4 Histopathological changes in the CNS of ET-1 treated and untreated SJL mice on 30 days post-TMEV infection. A Spinal cord sections of PBS (a) and ET-1 (b) treated mice were stained with LFB and counterstained through H\&E staining or through Bielschowsky silver staining $(c, d)$, respectively. Scale bars, $a-d=200 \mu \mathrm{m}$. B Cerebellum sections of PBS (e) and ET-1 (f) treated mice were stained with LFB/H\&E or Bielschowsky silver staining of the adjacent sections $(g, h)$, respectively. $g$ and $h$ showed the high magnification of the boxes in e and f. Scale bars, e-f $=100 \mu \mathrm{m} ; \mathrm{g}-\mathrm{h}=50 \mu \mathrm{m}$. Data are representative of three independent experiments with blinded sample labels

proliferative responses $(p<0.01)$ and IFN- $\gamma$ production $(p<0.001)$ by splenic $\mathrm{T}$ cells from the ET-1treated mice to PLP $(10 \mu \mathrm{M})$ at 20 days postimmunization were also greater than those of control (Fig. 6c). Further experiments showed that EAE development was similarly inhibited after administration of 


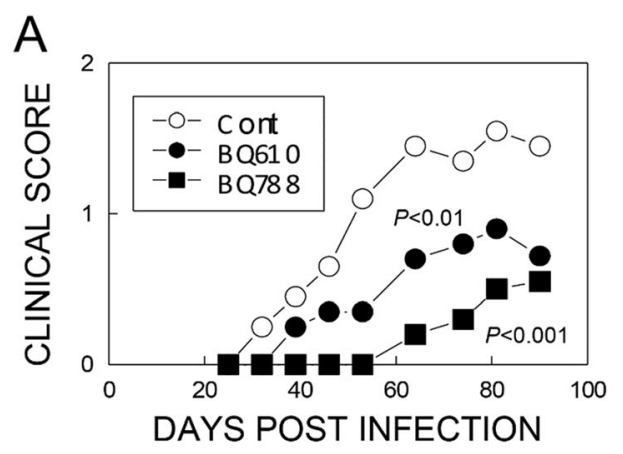

B
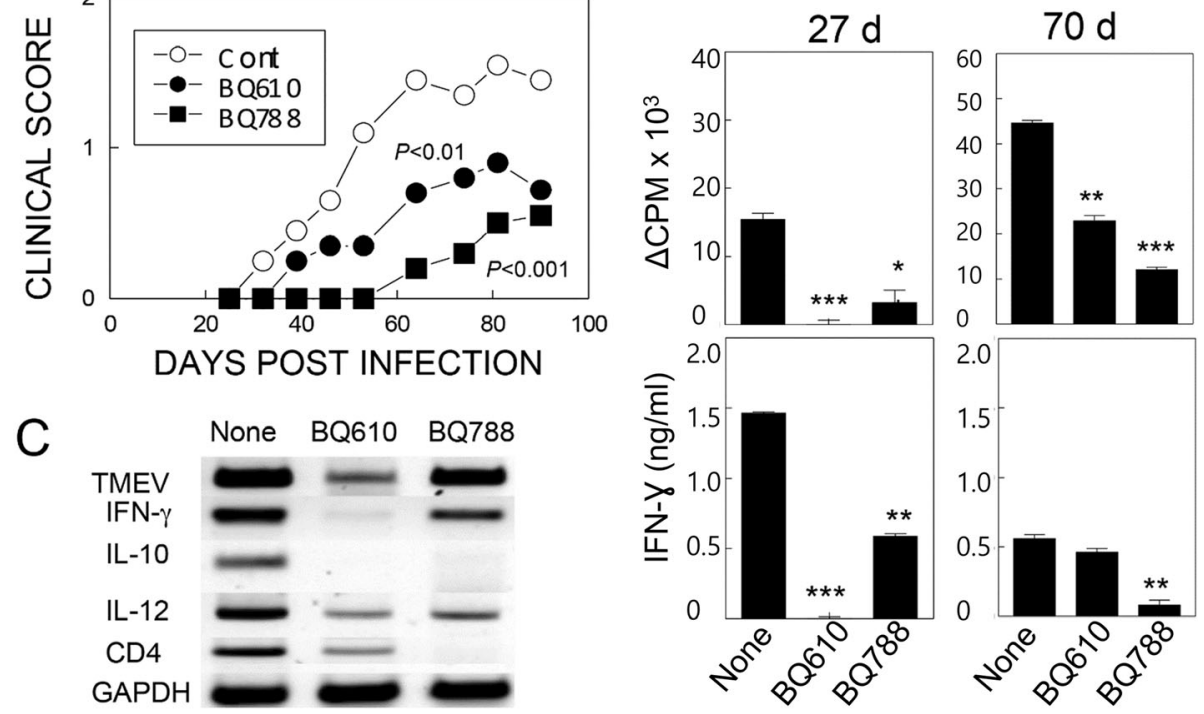

Fig. 5 Effects of endothelin receptor antagonists on the development of TMEV-induced demyelinating disease. Mice $(n=5 /$ group $)$ were infected with TMEV $\left(1 \times 10^{5} \mathrm{PFU}\right)$ and were treated with PBS (cont), BQ610, or BQ788 (1 mg/kg) at days 0, 5, 10, 15, 20, 30, and 46. a Disease course was determined using the 5-point scale. Statistical significance was determined by two-tailed paired $t$ test. $\mathbf{b}$ Proliferative responses and IFN- $\gamma$ production by splenic T cells to UV-TMEV at 27 and 70 dpi. c Comparison of cytokine message levels in the CNS of treated mice at $27 \mathrm{dpi}$ following RT-PCR. Data are presented as mean \pm SEM of three independent experiments. ${ }^{*} p<0.05,{ }^{* *} p<0.001$, and ${ }^{* * *} p<0.0001$

BQ788 $(p<0.05)$, but not BQ610 (Additional file 1: Supplementary Figure 2). These results are consistent with the previous observation with EAE [30] and similar to the effects on TMEV-IDD (Figs. 1 and 5).

\section{Discussion}

Infection of SJL mice with TMEV activates various cellular proteins via TLR2 and TLR3 $[14,15,34]$. ET-1 production is induced via TLR2, TLR3, and TLR4 [31-33]. In addition, ET-1 is produced in many different cell types and is associated with NF- $\mathrm{kB}$ activation [35, 36], which plays a critical role in TMEV replication $[45,46]$. ET-1 also induces COX-2 expression and PGE2 production [38], which significantly affect the pathogenesis of TMEV-induced demyelinating disease [19]. Therefore, it is plausible that TMEV infection induces ET-1 via TLR signaling and consequently affects development of TMEV-induced demyelinating disease. In this study, we explored the potential role of ET-1 in the development of TMEV-induced demyelinating disease.

First, we compared ET-1 levels in the CNS of SJL mice infected with TMEV and in uninfected control mice at 8 dpi (Fig. 1a). The level of ET-1 mRNA in the CNS was significantly elevated in TMEV-infected mice compared to uninfected mice, suggesting that infection of SJL mice with TMEV results in significantly higher ET-1 levels. This result is consistent with previous observations that viral infection elevates ET-1 production [32,33]. To further investigate the possible effects of elevated ET-1 on the development of TMEV-induced demyelinating disease, we administered the ET-1 peptide during early viral infection (Fig. 1b). Development of clinical symptoms was highly accelerated $(p<0.0024)$, accompanying elevation of CCL2 and CXCL1 chemokines which affect cellular infiltration in mice treated with ET-1 compared to the control mice. It was previously shown that ET-1 increases production of CCL2, CXCL1, and CXCL8 [47, 48]. Furthermore, these chemokines may also induce ET-1 production [49], which activates an amplification loop for the chemokines and ET-1. ET-1 is also known to enhance VCAM-1 expression on vascular endothelial cells and the dysfunction of endothelial cells [37]. This overproduction of chemokines, cytokines, and ET-1 in TMEV-infected mice may contribute to the pathogenesis of viral inflammatory disease by promoting cellular migration into the CNS. We also confirmed that the presence of a high level of ET-1 significantly elevates development of PLP $_{139-151}$-induced EAE in SJL mice (Fig. 6a), as shown previously in $\mathrm{MOG}_{35-55}$-induced $\mathrm{EAE}$ in C57BL/6 mice [30].

To verify the cellular migration into the CNS, cell types that infiltrated the CNS after TMEV infection were compared between the groups treated with ET-1 and PBS (Fig. 2). ET-1-treated mice showed significantly higher proportions of DCs, NK cells, macrophages, and granulocytes in the CNS compared to the control group during early viral infection. Levels of both IFN- $\gamma$ and IL17 mRNAs were significantly higher in $\mathrm{CD}_{4}^{+} \mathrm{T}$ cells, 

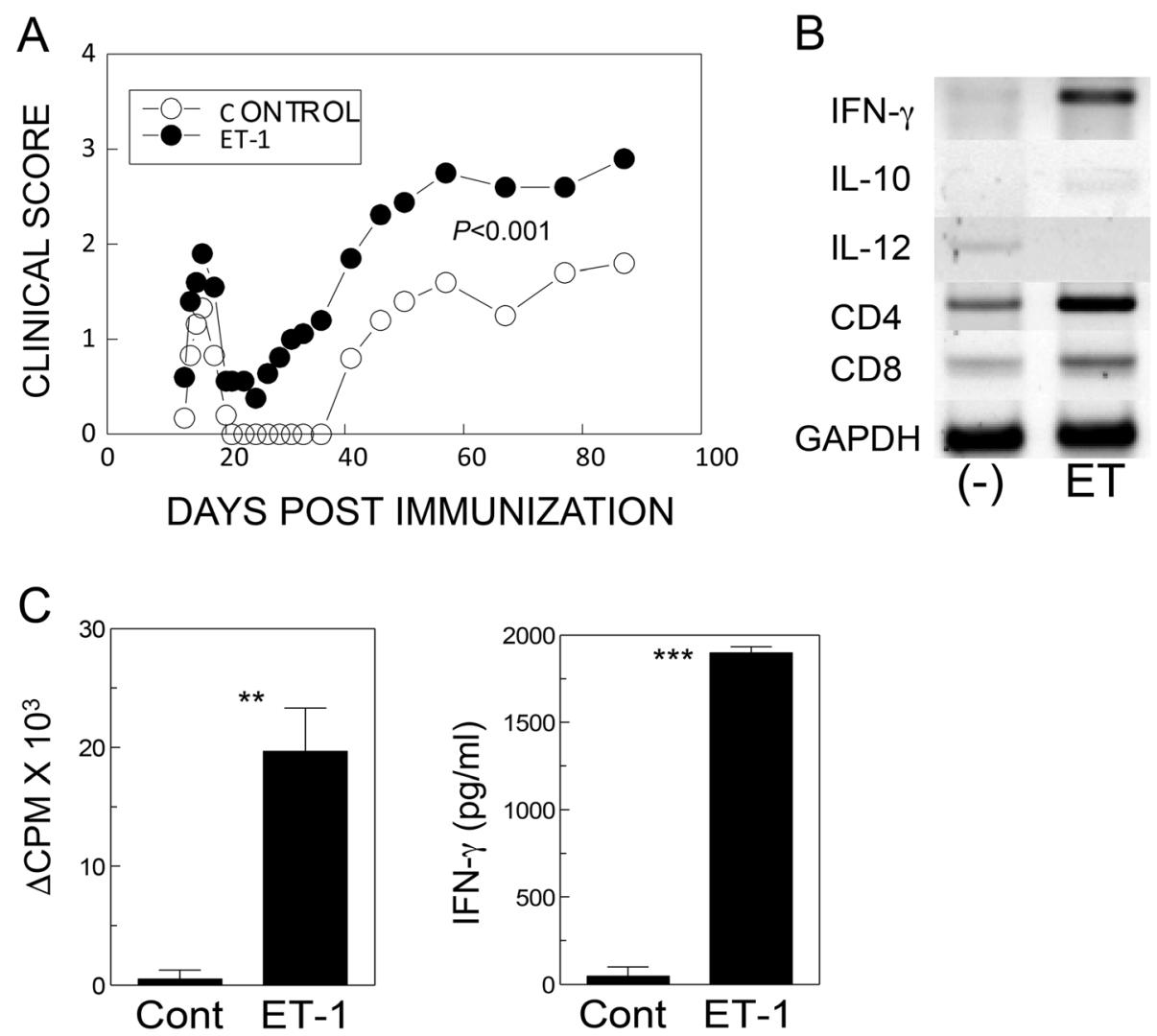

Fig. 6 Effect of endothelin-1 on PLP-induced EAE. a SJL/J mice ( $n=5 /$ group) were immunized with a suboptimal dose (10 $\mu \mathrm{g})$ of PLP and were injected with PBS or endothelin-1 at $20 \mu \mathrm{g} / \mathrm{kg}$ at $-3,0,5,10,15,20$, and 46 dpi. $p<0.001$ between control and ET-1 treated group based on two-tailed paired $t$ test between days 31 and 87 post-immunization. b Levels of CD4, CD8, and cytokine mRNA in the CNS of treated mice. $\mathbf{c}$ Proliferative responses and IFN- $\gamma$ production by splenic T cells from control and ET-1 treated mice $(n=3)$ to PLP $(10 \mu M)$ at 20 days after PLPimmunization. Data are presented as mean \pm SEM of three independent experiments. ${ }^{* *} p<0.001$, and ${ }^{* * *} p<0.0001$

and only the IFN- $\gamma$ mRNA level was higher in $\mathrm{CD}^{+} \mathrm{T}$ cells in ET-1-treated mice (Fig. 3). Histological examination of the spinal cords and brains of mice infected with TMEV at 30 dpi showed that there are more infiltrating lymphocytes/macrophages that accumulated in both the spinal cord and cerebellum of ET-1-treated SJL mice, but these accumulated only in the spinal cord of the control SJL mice (Fig. 4). Cellular infiltration was mainly present in the white matter in control SJL mice in contrast to the infiltration into the gray matter of the spinal cord and cerebellum of the ET-1-treated SJL mice. It was previously shown that development of TMEVinduced demyelinating disease accompanies cellular infiltration that is limited to the white matter in the spinal cord $[8,50]$, as seen in the TMEV-infected control SJL mice. However, ET-1 treated TMEV-infected SJL mice showed that the cellular infiltration extended to the gray matter of the spinal cord and brain. These results strongly suggest that excess levels of ET-1 during viral infection further exacerbates cellular infiltration and inflammation in the CNS.
However, the above experiments do not directly prove the direct involvement of ET-1 in the pathogenesis of TMEV-induced demyelinating disease. As such, we further investigated the potential role of ET-1 in the development of TMEV-induced demyelinating disease by administering ET-1 receptor inhibitors (BQ610 or BQ788) during viral infection (Fig. 5). Administration of either ET-1 receptor inhibitor significantly decreased development of TMEV-IDD accompanied with decreased levels of T cell responses to the virus. ET-1 receptor inhibitors have previously been successfully used to define the role of ET-1 in various clinical and experimental diseases [5153] including EAE [29]. Thus, the lack of ET-1 function during viral infection inhibits TMEV-IDD development, indicating that the presence of ET-1 during viral infection significantly contributes to the pathogenesis of TMEVinduced demyelinating disease in susceptible SJL mice.

\section{Conclusions}

Thus, we concluded that the presence of ET-1 plays an important role in the pathogenesis of TMEV-induced 
demyelinating disease. TMEV infection triggers ET-1 production, most likely via TLRs [14, 15, 31-34]. Consequently, TLR-mediated signals activate the NLRP3 and $\mathrm{NF}-\mathrm{KB}$ pathways, which are associated with production of various inflammatory chemokines and cytokines, as well as with viral replication $[19,21,45,46]$. These chemokines and cytokines may be further engaged in an amplification loop of ET-1, which are involved in cellular infiltration into the CNS and in promoting inflammatory responses [47-49]. In addition, ET-1 and NLRP3 that are activated following TMEV infection [19] may also participate in PGE2 production [38], causing a skew to the development of pathogenic Th17 and Tc17 responses $[5,6]$.

\section{Supplementary information}

Supplementary information accompanies this paper at https://doi.org/10. 1186/s12974-020-01986-z

\section{Additional file 1: Supplementary Figure 1 Effects of endothelin} administration on the expression of inhibitory and co-stimulatory molecules on monocytes $\left(C D 11 b^{+}\right)$in the CNS of infected mice. The percent age of inhibitory (PDL-1) and co-stimulatory molecules (CD40, CD80, CD86, and MHC) expressed on CNS CD11 b cells among the total CNS CD $11 b^{+}$cells from TMEV-infected mice treated with either PBS or ET-1 (each, $n=3$ ) at $8 \mathrm{dpi}($ mean $\pm \mathrm{SD}$ ). Data are representative of three independent experiments. ${ }^{*}, p<0.05$, and ${ }^{* *}, p<0.001$. Supplementary Figure 2. Effect of endothelin receptor antagonist treatment on PLP-induced EAE. Mice ( $n=5 /$ group) was immunized with optimal dose $(40 \mu \mathrm{g} P \mathrm{PL})$ and treated with PBS (cont), BQ610, or BQ788 (1 mg/kg) at 0, 5, 10, 15, 20,30, and $46 \mathrm{dpi}$. The disease course was determined using the 5-point scale. BQ788 treated group was significantly $(p<0.045)$ different from other groups based on two-tailed paired t test between 50-76 dpi.

\section{Abbreviations}

MS: Multiple sclerosis; TMEV: Theiler's murine encephalomyelitis virus; TMEVIDD: TMEV-induced demyelinating disease; EAE: Experimental allergic encephalitis; CNS: Central nervous system

\section{Acknowledgements}

Not applicable.

\section{Authors' contributions}

$\mathrm{Y}-\mathrm{HJ}$ did the investigation, visualization and writing of the review, and editing. BK did investigation. HSK did the investigation. C-SK did the investigation. BSK did the conceptualization, funding acquisition, supervision, and writing of the original draft. The authors read and approved the final manuscript.

\section{Funding}

This work was supported by the National Institute of Neurological Disorders and Stroke Grants [grant numbers RO1 NS28752 and RO1 NS33008] and the National Research Council of Science and Technology (NST) grant [grant numbers CRC-16-01-KRICT and NSN1622460] funded by the Korea government (MSIT)

\section{Availability of data and materials}

The datasets supporting the conclusions of this article are included within the article and its additional files.

\section{Ethics approval and consent to participate}

Experimental procedures with mice were conducted in accordance with the $\mathrm{NIH}$ animal care guidelines and were approved by the animal care and use committee of Northwestern University (\#2011-1316).

\section{Consent for publication}

Consents for publication are obtained.

\section{Competing interests}

The authors declare that they have no competing interests.

\section{Author details}

${ }^{1}$ Department of Microbiology-Immunology, Northwestern University Feinberg Medical School, 303 East Chicago Avenue, Chicago, IL 60611, USA. ${ }^{2}$ KM Application Center, Korea Institute of Oriental Medicine, Daegu, Republic of Korea. ${ }^{3}$ Center for Convergent Research of Emerging Virus Infection, Korea Research Institute of Chemical Technology, Daejeon, Republic of Korea. ${ }^{4}$ Department of Biomedical Laboratory Sciences, Graduate School of Medicine, Shinshu University, Matsumoto, Nagano 390-8621, Japan.

Received: 17 August 2020 Accepted: 6 October 2020

Published online: 17 October 2020

\section{References}

1. Lipton HL, Dal Canto MC. Chronic neurologic disease in Theiler's virus infection of SJL/J mice. J Neurol Sci. 1976;30:201-7.

2. Dal Canto MC, Melvold RW, Kim BS, Miller SD. Two models of multiple sclerosis: experimental allergic encephalomyelitis (EAE) and Theiler's murine encephalomyelitis virus (TMEV) infection. A pathological and immunological comparison. Microsc Res Tech. 1995:32:215-29.

3. Miller S, Gerety S, Kennedy M, Peterson J, Trotter J, Touhy V, et al. Class II restricted responses in Theiler's murine encephalomyelitis virus (TMEV)induced demyelinating disease. III. Failure of neuroantigen-specific immune tolerance to affect the clinical course of demyelination. J Neuroimmunol. 1990;26:9-23.

4. Palma JP, Yauch RL, Lang S, Kim BS. Potential role of CD4+ T cell-mediated apoptosis of activated astrocytes in Theiler's virus-induced demyelination. J Immunol. 1999;162:6543-51.

5. Hou W, Kang HS, Kim BS. Th17 cells enhance viral persistence and inhibit T cell cytotoxicity in a model of chronic virus infection. J Exp Med. 2009;206: 313-28.

6. Myoung J, Kang HS, Hou W, Meng L, Dal Canto MC, Kim BS. Epitope-specific CD8+ T cells play a differential pathogenic role in the development of a viral disease model for multiple sclerosis. J Virol. 2012;86:13717-28.

7. Leibowitz JL, Rodriguez M. Antigenic variants are not selected during persistent infection with Theiler's virus. InfectImmun. 1983;41:440-2.

8. Dal Canto MC, Kim BS, Miller SD, Melvold RW. Theiler's murine encephalomyelitis virus (TMEV)-induced demyelination: a model for human multiple clerosis. Methods. 1996:10:453-61.

9. Kim BS, Lyman MA, Kang BS, Kang HK, Lee HG, Mohindru M, et al. Pathogenesis of virus-induced immune-mediated demyelination. Immunol Res. 2001:24:121-30.

10. Rauch HC, Montgomery IN, Hinman CL, Harb W, Benjamins JA. Chronic Theiler's virus infection in mice: appearance of myelin basic protein in the cerebrospinal fluid and serum antibody directed against MBP. JNeuroimmunol. 1987:14:35-48.

11. Fujinami RS, Zurbriggen A, Powell HC. Monoclonal antibody defines determinant between Theiler's virus and lipid-like structures. J Neuroimmunol. 1988;20:25-32.

12. Miller SD, Vanderlugt CL, Begolka WS, Pao W, Yauch RL, Neville KL, et al. Persistent infection with Theiler's virus leads to CNS autoimmunity via epitope spreading. Nat Med. 1997:3:1133-6.

13. Jin Y-H, Kim CX, Huang J, Kim BS. Infection and activation of B cells by Theiler's murine encephalomyelitis virus (TMEV) leads to autoantibody production in an infectious model of multiple sclerosis. Cells. 2020;9:E1787.

14. So EY, Kang MH, Kim BS. Induction of chemokine and cytokine genes in astrocytes following infection with Theiler's murine encephalomyelitis virus is mediated by the toll-like receptor 3. Glia. 2006;53:858-67.

15. So EY, Kim BS. Theiler's virus infection induces TLR3-dependent upregulation of TLR2 critical for proinflammatory cytokine production. Glia. 2009;57:1216-26.

16. Jin YH, Kim SJ, So EY, Meng L, Colonna M, Kim BS. Melanoma differentiation-associated gene 5 is critical for protection against Theiler's virus-induced demyelinating disease. J Virol. 2012;86:1531-43. 
17. Jin YH, Hou W, Kim SJ, Fuller AC, Kang B, Goings G, et al. Type I interferon signals control Theiler's virus infection site, cellular infiltration and T cell stimulation in the CNS. J Neuroimmunol. 2010;226:27-37.

18. Kim BS, Jin YH, Meng L, Hou W, Kang HS, Park HS, et al. IL-1 signal affects both protection and pathogenesis of virus-induced chronic CNS demyelinating disease. J Neuroinflammation. 2012;9:217.

19. Kim SJ, Jin YH, Kim BS. Prostaglandin E2 produced following infection with Theiler's virus promotes the pathogenesis of demyelinating disease. PLoS One. 2017;12:e0176406.

20. Palma JP, Kim BS. Induction of selected chemokines in glial cells infected with Theiler's virus. J Neuroimmunol. 2001;117:166-70.

21. Palma JP, Kim BS. The scope and activation mechanisms of chemokine gene expression in primary astrocytes following infection with Theiler's virus. J Neuroimmunol. 2004;149:121-9.

22. Ure DR, Lane TE, Liu MT, Rodriguez M. Neutralization of chemokines RANTES and MIG increases virus antigen expression and spinal cord pathology during Theiler's virus infection. Int Immunol. 2005;17:569-79.

23. Karpus WJ, Kennedy KJ, Fife BT, Bennett JL, Dal Canto MC, Kunkel SL, et al. Anti-CCL2 treatment inhibits Theiler's murine encephalomyelitis virusinduced demyelinating disease. J Neurooncol. 2006;12:251-61.

24. Kang $\mathrm{MH}$, Jin $\mathrm{YH}$, Kim BS. Effects of keratinocyte-derived cytokine (CXCL-1) on the development of Theiler's virus-induced demyelinating disease. Front Cell Infect Microbiol. 2018;8:9.

25. Vadasz Z, Attias D, Kessel A, Toubi E. Neuropilins and semaphorins-from angiogenesis to autoimmunity. Autoimmun Rev. 2010;9:825-9.

26. Roscoe WA, Welsh ME, Carter DE, Karlik SJ. VEGF and angiogenesis in acute and chronic MOG((35-55)) peptide induced EAE. J Neuroimmunol. 2009;209: 6-15.

27. Girolamo F, Coppola C, Ribatti D, Trojano M. Angiogenesis in multiple sclerosis and experimental autoimmune encephalomyelitis. Acta Neuropathol Commun. 2014;2:84.

28. Haufschild T, Shaw SG, Kesselring J, Flammer J. Increased endothelin-1 plasma levels in patients with multiple sclerosis. J Neuroophthalmol. 2001; 21:37-8.

29. Shin T, Kang B, Tanuma N, Matsumoto Y, Wie M, Ahn M, et al. Intrathecal administration of endothelin-1 receptor antagonist ameliorates autoimmune encephalomyelitis in Lewis rats. Neuroreport. 2001;12:1465-8.

30. Guo Y, Chung SK, Siu CW, Kwan SC, Ho PW, Yeung PK, et al. Endothelin-1 overexpression exacerbate experimental allergic encephalomyelitis. J Neuroimmunol. 2014;276:64-70.

31. Spirig R, Potapova I, Shaw-Boden J, Tsui J, Rieben R, Shaw SG. TLR2 and TLR4 agonists induce production of the vasoactive peptide endothelin-1 by human dendritic cells. Mol Immunol. 2009;46:3178-82.

32. Farina G, York M, Collins C, Lafyatis R. dsRNA activation of endothelin-1 and markers of vascular activation in endothelial cells and fibroblasts. Ann Rheum Dis. 2011;70:544-50.

33. George PM, Badiger R, Shao D, Edwards MR, Wort SJ, Paul-Clark MJ, et al. Viral toll like receptor activation of pulmonary vascular smooth muscle cells results in endothelin-1 generation; relevance to pathogenesis of pulmonary arterial hypertension. Biochem Biophys Res Commun. 2012;426:486-91.

34. Jin $\mathrm{YH}$, Kang HS, Hou W, Meng L, Kim BS. The level of viral infection of antigen-presenting cells correlates with the level of development of Theiler's murine encephalomyelitis virus-induced demyelinating disease. J Virol. 2015;89:1867-78.

35. Kowalczyk A, Kleniewska P, Kolodziejczyk M, Skibska B, Goraca A. The role of endothelin-1 and endothelin receptor antagonists in inflammatory response and sepsis. Arch Immunol Ther Exp (Warsz). 2015;63:41-52.

36. Yeager ME, Belchenko DD, Nguyen CM, Colvin KL, Ivy DD, Stenmark KR. Endothelin-1, the unfolded protein response, and persistent inflammation: role of pulmonary artery smooth muscle cells. Am J Respir Cell Mol Biol. 2012:46:14-22

37. Li L, Chu Y, Fink GD, Engelhardt JF, Heistad DD, Chen AF. Endothelin-1 stimulates arterial VCAM-1 expression via NADPH oxidase-derived superoxide in mineralocorticoid hypertension. Hypertension. 2003;42:9971003.

38. Lin CC, Hsieh HL, Shih RH, Chi PL, Cheng SE, Yang CM. Up-regulation of COX-2/PGE2 by endothelin-1 via MAPK-dependent NF-kappaB pathway in mouse brain microvascular endothelial cells. Cell Commun Signal. 2013;11:8.

39. Hynynen MM, Khalil RA. The vascular endothelin system in hypertension-recent patents and discoveries. Recent Pat Cardiovasc Drug Discov. 2006;1:95-108.
40. Yauch RL, Kim BS. A predominant viral epitope recognized by T cells from the periphery and demyelinating lesions of $\mathrm{SJL} / \mathrm{J}$ mice infected with Theiler's virus is located within VP1(233-244). J Immunol. 1994;153:4508-19.

41. Anonymous. Experimental allergic encephalomyelitis: a useful model for multiple sclerosis. New York: Alan R. Liss, Inc.; 1984.

42. Tuohy VK, Lu Z, Sobel RA, Laursen RA, Lees MB. Identification of an encephalitogenic determinant of myelin proteolipid protein for SJL mice. J Immunol. 1989;142:1523-7.

43. Jin YH, Kim BS. Isolation of CNS-infiltrating and resident microglial cells. Bio Protoc. 2015;5:e1385.

44. Wang $\mathrm{HHHH}$, Wu CY, Yang CM. Endothelin-1 enhances cell migration via matrix metalloproteinase-9 up-regulation in brain astrocytes. J Neurochem. 2010;113:1133-49.

45. Palma JP, Kwon D, Clipstone NA, Kim BS. Infection with Theiler's murine encephalomyelitis virus directly induces proinflammatory cytokines in primary astrocytes via NF-kappaB activation: potential role for the initiation of demyelinating disease. J Virol. 2003;77:6322-31.

46. Kang MH, So EY, Park H, Kim BS. Replication of Theiler's virus requires NFkappaB-activation: higher viral replication and spreading in astrocytes from susceptible mice. Glia. 2008;56:942-53.

47. Koyama Y, Kotani M, Sawamura T, Kuribayashi M, Konishi R, Michinaga S. Different actions of endothelin-1 on chemokine production in rat cultured astrocytes: reduction of CX3CL1/fractalkine and an increase in CCL2/MCP-1 and CXCL1/CINC-1. J Neuroinflammation. 2013;10:51.

48. Mangahas CR, dela Cruz GV, Friedman-Jimenez G, Jamal S. Endothelin-1 induces CXCL1 and CXCL8 secretion in human melanoma cells. J Invest Dermatol. 2005;125:307-11.

49. Molet S, Furukawa K, Maghazechi A, Hamid Q, Giaid A. Chemokine- and cytokine-induced expression of endothelin 1 and endothelin-converting enzyme 1 in endothelial cells. J Allergy Clin Immunol. 2000;105:333-8.

50. Lipton HL. Theiler's virus infection in mice: an unusual biphasic disease process leading to demyelination. Infectlmmun. 1975;11:1147-55.

51. Ortega Mateo A, de Artinano AA. Highlights on endothelins: a review. Pharmacol Res. 1997;36:339-51

52. Iglarz M, Clozel M. Mechanisms of ET-1-induced endothelial dysfunction. J Cardiovasc Pharmacol. 2007;50:621-8.

53. Neuhofer W, Pittrow D. Endothelin receptor selectivity in chronic kidney disease: rationale and review of recent evidence. Eur J Clin Invest. 2009; 39(Suppl 2):50-67.

\section{Publisher's Note}

Springer Nature remains neutral with regard to jurisdictional claims in published maps and institutional affiliations.

Ready to submit your research? Choose BMC and benefit from:

- fast, convenient online submission

- thorough peer review by experienced researchers in your field

- rapid publication on acceptance

- support for research data, including large and complex data types

- gold Open Access which fosters wider collaboration and increased citations

- maximum visibility for your research: over $100 \mathrm{M}$ website views per year

At $\mathrm{BMC}$, research is always in progress.

Learn more biomedcentral.com/submissions 